Revue d'histoire de l'enfance « irrégulière »

Le Temps de l'histoire

$7 \mid 2005$

Enfermements et éducations

\title{
Ivan Jablonka : Les vérités inavouables de Jean Genet
}

\section{Pierre Segond}

\section{(2) OpenEdition}

\section{Journals}

Édition électronique

URL : http://journals.openedition.org/rhei/402

DOI : $10.4000 /$ rhei.402

ISBN : 978-2-7535-1645-8

ISSN : 1777-540X

Éditeur

Presses universitaires de Rennes

Édition imprimée

Date de publication : 15 novembre 2005

Pagination : 320-321

ISSN : 1287-2431

Référence électronique

Pierre Segond, «Ivan Jablonka : Les vérités inavouables de Jean Genet », Revue d'histoire de l'enfance " irrégulière » [En ligne], 7 | 2005, mis en ligne le 06 février 2007, consulté le 03 décembre 2020. URL : http://journals.openedition.org/rhei/402 ; DOI : https://doi.org/10.4000/rhei.402

(c) PUR 
Ivan Jablonka

Les vérités inavouables de Jean Genet,

Paris, Seuil, Coll. XXème siècle, 2004, 437 p.

"Essai d'histoire littéraire », ce livre n'est pas une nouvelle biographie du poète Jean Genet, même si son auteur, Ivan Jablonka, revisite celle-ci pour conduire, avec une méthode rigoureuse, une approche totalement nouvelle de l'élaboration progressive du "mythe Genet" de Cocteau à Sartre. Partant du postulat qu' " on ne naît pas grand écrivain, on le devient par une stratégie ", Ivan Jablonka s'emploie à en faire la démonstration à travers une analyse extrêmement fine de la trajectoire du poète depuis son enfance jusqu'à ses derniers écrits, en la confrontant au contexte tant historique que littéraire du XXème siècle dans lequel elle s'inscrit. Démasquant le personnage et les divers travestissements dont il fut affublé par ses thuriféraires, il s'efforce de faire apparaître la personne de Genet dans toutes ses contradictions et dans sa vérité, au-delà des jeux, des manipulations et du mythe.

Ayant eu accès pour la première fois au dossier de Jean Genet à l'Assistance publique de la Seine, qui figure dans les archives de la DASES (dossier totalement inédit jusqu’ici, qui court sur la période 1911-1930), Ivan Jablonka en exploite avec rigueur tous les documents pour faire apparaître - par une étude comparative avec les données recueillies sur les trajectoires d'autres pupilles contemporains et la réalité des pratiques éducatives de l'Assistance publique à la même époque - le sort privilégié de l'enfant Genet au sein d'une famille d'accueil chaleureuse et bienveillante. Loin d'être en proie à un destin à la Cosette, inventé par les conceptions "romantiques" de Sartre, il fut choyé et soutenu tant par ses proches que par l'administration de l'AP ellemême, au point que l'on peut évoquer une problématique d'“enfant-roi" se vivant humilié et rejeté vers la marginalité par une non-reconnaissance de ses dons. Certes, il a dû souffrir d'un étiquetage social d'enfant de l'AP, dans son village, tout comme ses semblables (en dépit de l'entourage familial de bonne qualité) ; mais la vraie rupture se situe au moment de sa première fugue provoquée par son placement dans un centre d'apprentissage des métiers du livre, comme si, se vivant déjà comme un écrivain aspirant à une haute des-

Pierre Segond / p. 320 à 321 
tinée, il était ramené au niveau du simple typographe, s'enfonçant dès lors dans une problématique de l'humiliation. Bien qu'il s'agisse d'une formation qui, en soi, était déjà une orientation privilégiée dans le cadre de l'AP, elle ne répondait pas à son aspiration d'être "distingué" pour poursuivre des études secondaires et, peut-être, accéder aux grandes écoles. Il se trouvait, de fait, réduit à « l'École anormale supérieure » de Mettray...

C'est autour de ces données que s'articule une "déconstruction" du mythe et du personnage, fondée sur les travaux de Bourdieu, Derrida, Ricœur et Jauss, dans une tentative réussie pour resituer les racines de l'écriture de Genet et de son œuvre dans l'histoire littéraire de son temps, mettant en évidence son idéalisation esthétique et ses connivences avec celles de Brasillach, Morand, Drieu la Rochelle et quelques autres représentants du fascisme littéraire. Ayant été promu sur la scène littéraire par Jean Cocteau dans un contexte de Collaboration, Genet se coulera, à la Libération, dans une récupération de gauche opérée par Jean-Paul Sartre (dont le titre Saint-Genet, comédien et martyr est finalement plus proche de la réalité que ne le sont ses analyses). Enfin l'analyse de leurs relations complexes les réunit en un aristocratisme partagé.

La richesse du livre d'Ivan Jablonka est telle que l'on ne peut que renvoyer à sa lecture, rendue plus attrayante encore par la fluidité du style. De plus, cet ouvrage permet de voir à l'œuvre une " méthode critique assortie d'une conception de la geste créatrice qui renouvelle la critique littéraire " (A. Dufour). L'entreprise est d'autant plus réussie qu'elle conduit le lecteur à retourner à l'œuvre même, car, comme Ivan Jablonka le souligne lui-même avec justesse, « la jouissance de l'œuvre littéraire peut être accrue par la compréhension hors-texte qu'on acquiert d'elle».

Une seule réserve cependant concerne le titre retenu par l'éditeur et qui peut engendrer un malentendu sur l'objet du livre et ses perspectives : il ne faudrait surtout pas passer à côté de cet incontournable essai critique d'histoire littéraire (qui, par sa méthode, dépasse largement son objet) en le prenant pour un pamphlet de plus sur Jean Genet. Un tel contresens serait très dommageable, et il semble malheureusement ne pas avoir été évité par certains critiques (dont les silences sont assourdissants...).

Pierre Segond 